\title{
Synthesis of vegetable-oil based polymer by terpolymerization of epoxidized soybean oil, propylene oxide and carbon dioxide
}

\author{
Farra Wahida Shaarani ${ }^{\mathrm{a}, \mathrm{b}}$, Jordi J. Bou ${ }^{\mathrm{a}, *}$ \\ a Department of Chemical Engineering, Escola Tècnica Superior d'Enginyeria Industrial de Barcelona, Universitat Politècnica de Catalunya, Barcelona Tech, Diagonal 647, \\ 08028 Barcelona, Spain \\ ${ }^{\mathrm{b}}$ Section of Chemical Engineering, Universiti Kuala Lumpur, International College, 1016, Jalan Sultan Ismail, 50250 Kuala Lumpur, Wilayah Persekutuan Kuala Lumpur, \\ Malaysia
}

\section{A R T I C L E I N F O}

Article history:

Received 1 November 2016

Received in revised form 22 April 2017

Accepted 24 April 2017

Available online $\mathrm{xxx}$

\section{Keywords:}

Renewable bio-resources

Natural epoxide

Double metal cyanide

Bio-based polymer

Polycarbonate

\section{A B S T R A C T}

Although carbon dioxide $\left(\mathrm{CO}_{2}\right)$ is well known as one of the major green-house gases, it is also an economical $\mathrm{C} 1$ resource. Thus, $\mathrm{CO}_{2}$ has been regarded as an appealing starting material for the synthesis of polymers, like polycarbonates by the reaction with epoxides. Herein the reaction between natural epoxidized soybean oil (ESO), propylene oxide (PO) and $\mathrm{CO}_{2}$ under high pressure $(4.0 \mathrm{MPa})$ with the presence of Co- $\mathrm{Zn}$ double metal cyanide (Co-Zn DMC) catalyst was studied. Temperature and reaction time were varied accordingly and the products obtained were characterized by FTIR, GPC and ${ }^{1} \mathrm{H}$ NMR. The results obtained indicate the formation of polycarbonates in the samples collected with yields vary from 60 to $85 \%$. The number average molecular weight $\left(M_{n}\right)$ of the resultant polymer prepared at reaction temperature of $80{ }^{\circ} \mathrm{C}$ and reaction time of $6 \mathrm{~h}$ can reach up to $6498 \mathrm{~g} / \mathrm{mol}$.

(C) 2016 Published by Elsevier Ltd.

\section{Introduction}

The rising levels of carbon dioxide $\left(\mathrm{CO}_{2}\right)$ in the atmosphere are linked to global warming and this phenomenon is becoming a pressing environmental issue. Thus continuous efforts are being made to mitigate the atmospheric $\mathrm{CO}_{2}$ concentration via carbon capture and storage. The aforementioned technique is quite popular and received considerable attention among researchers in recent years. This technique requires $\mathrm{CO}_{2}$ to be removed from the flue gases of large emitters such as power plant by means of membrane separation or an absorbent/adsorbent such as monoethanolamine (MEA) (Coutris et al., 2015). Following to this step, the captured $\mathrm{CO}_{2}$ then stored in the underground reservoirs. In spite of the fact that this method has great potential in reducing the amount of $\mathrm{CO}_{2}$ entering the atmosphere, the thought of retaining huge $\mathrm{CO}_{2}$ reservoirs is not very appealing. In view of that, a more meaningful strategy such as utilization of $\mathrm{CO}_{2}$ by its conversion into valuable materials and products is expected to subsidized carbon capture and sequestration processes. Furthermore the use of $\mathrm{CO}_{2}$ as a chemical feedstock is ideal since it is abundantly available, inexpensive, non-toxic and non-hazardous (Taşc1 and Ulusoy, 2012; Wang et al., 2012).

One of the popular approaches is to use $\mathrm{CO}_{2}$ as co-monomer in polymerization reactions. In this context, the catalytic copolymerization of epoxides and $\mathrm{CO}_{2}$ emerges as a promising technology

\footnotetext{
* Corresponding author

Email address: jordi.bou@upc.edu (J.J. Bou)
}

(Sakakura et al., 2007). In the year of 1969, Inoue and coworkers have successfully synthesized poly(propylene carbonate) from propylene oxide (PO) and $\mathrm{CO}_{2}$ by using $\mathrm{ZnEt}_{2}$ and water as catalyst (Inoue et al., 1969). To date substantial amount of literatures are available revealing different types of outstanding catalyst for the copolymerization process (Ang et al., 2015; Meng et al., 2016; Trott et al., 2016) ever since their discovery. Simultaneously, a number of epoxides and diverse operating conditions for the coupling of $\mathrm{CO}_{2}$ and epoxides have been reported by devoted researchers (Dai et al., 2016; Darensbourg and Chung, 2014; Oh and Ko, 2013; Sebastian and Srinivas, 2014; Tang et al., 2013). Despite of the countless references available in this field, very few reported on the utilization of renewable bio-resources specifically vegetable oil-based epoxide in copolymerization with $\mathrm{CO}_{2}$.

Usage of vegetable oil-based epoxide as a starting material can be considered as an interesting strategy to enhance the green content of the polymers. Moreover, it may serve as a substitute to the traditional epoxide which is petroleum based. Owing to the heavy dependence of mankind on fossil fuels and its current consumption rates, the worldwide fossil fuel reserves are depleting rapidly (Ingrao et al., 2015). Hence, it is essential to find an alternative starting material from renewable resources since it can provide both environmental and economic sustainability.

Soybean oil, particularly, is a vegetable oil with interest in polymer since its abundant availability, reactive functionalities and competitive cost (Costa et al., 2016; Miao et al., 2014). This renewable material is composed of triglycerides, which are the major component of plant oil. Triglycerides are formed from three various fatty acid 
chains joined by a glycerol center. The major composition of fatty acid in soybean oil is linoleic acid with 53\% and soybean oil has an average of 4.6 double bonds per molecule (Xia and Larock, 2010).

Polycarbonates are a class of thermoplastic polymers with carbonate linkages in their chemical structure. Commonly, they are categorized as aliphatic or aromatic polycarbonate, depending on the structure of the $\mathrm{R}$ groups. The general structure of polycarbonate is shown in Fig. 1. The conventional method to synthesized polycarbonate is by the reaction between Bisphenol A (BPA) and phosgene $\left(\mathrm{COCl}_{2}\right)$ which results an amorphous polymer with high impact strength, toughness, heat resistance and transparency. These exceptional properties made them a versatile material with substantial industrial significance. Although BPA-based polycarbonate produced excellent properties of products, on the other hand it also has some drawbacks such as the usage of highly poisonous phosgene and chlorinated solvents. Utilization of BPA itself as a monomer caused a great anxiety regarding negative health effects due to leaching out of the polymer when in contact with food (US Food and Drug Administration, 2014). Additionally both monomers used are fossil-based compounds.

From the environmental point of view, copolymerization of natural epoxides with $\mathrm{CO}_{2}$ may lead to significant environmental impacts since they contribute to reduce the atmospheric emissions of $\mathrm{CO}_{2}$, circumvent the use of very toxic and hazardous phosgene in the traditional route of polycarbonate production and involve the use of renewable bio-resources like vegetable oils which will lessen the dependency on the petroleum based routes of synthesis.

Therefore in the present work, an attempt was made to terpolymerize ESO, $\mathrm{PO}$ and $\mathrm{CO}_{2}$ in the presence of heterogeneous catalyst namely Co-Zn Double Metal Cyanide (Co-Zn DMC). The reaction takes place at fixed $\mathrm{CO}_{2}$ pressure of $4.0 \mathrm{MPa}$ with equal volume of $\mathrm{ESO}$ and $\mathrm{PO}$. The reaction temperature and reaction time were varied in the range of $60-100{ }^{\circ} \mathrm{C}$ and 6-72 $\mathrm{h}$ and respectively. Under the conditions studied, the resultant products yield a mixture of polycarbonate, cyclic carbonate and polyether.

\section{Experimental}

\subsection{Material}

ESO with approximately 4.5 oxirane rings per triglyceride (Fig. 2) obtained from Traquisa (Barbera del Valles, Barcelona Spain) was used in this research work whereas PO $(>99 \%)$ was supplied by Sigma Aldrich. Materials, such as potassium hexacyanocobatate(III) $\left(\mathrm{K}_{3} \mathrm{Co}(\mathrm{CN})_{6}\right)$, zinc chloride $\left(\mathrm{ZnCl}_{2}\right)$, and tertiary butyl alcohol (tert-

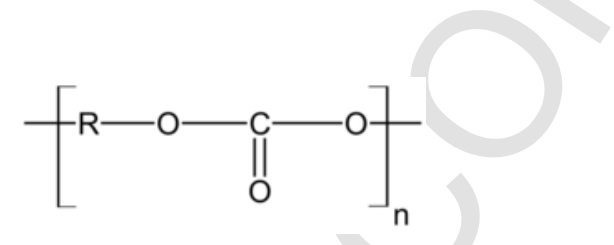

butanol) were used without further purification. $\mathrm{CO}_{2}$ with a purity of $99.99 \%$ was used as received. Other solvents such as chloroform, dimethyl sulfoxide (DMSO), hexafluoroisopropanol (HFIP), methylene chloride, methanol and toluene were of analytical reagent grade and used without further purification.

\subsection{Preparation of the catalyst}

Co-Zn DMC catalyst was prepared in the presence of tert-butanol as complexing agent. The method of preparation was according to the procedure outlined by Li et al. (2011) (Li et al., 2011). Briefly, solution 1 was prepared by dissolving $6.64 \mathrm{~g}$ of $\mathrm{K}_{3} \mathrm{Co}(\mathrm{CN})_{6}$ in $100 \mathrm{~mL}$ of double distilled water meanwhile solution 2 was made by dissolving $80 \mathrm{~g}$ of $\mathrm{ZnCl}_{2}$ in $300 \mathrm{~mL}$ of double distilled water and $150 \mathrm{~mL}$ of tert-butanol. Solution 1 was added dropwise to solution 2 over a period of one hour and the mixture was kept for aging at $50{ }^{\circ} \mathrm{C}$ for another two hours under vigorous stirring. The resulted white suspension was filtered and centrifuged in order to segregate the Co-Zn DMC complex. The white precipitate collected was redispersed in a solution of tert-butanol and water $(1: 1 \mathrm{v} / \mathrm{v})$ using high speed stirring. This step was repeated serially by increasing the volume ratio of tert-butanol to water $(6: 4,7: 3,8: 2$, and 9:1, respectively). Finally, the solid was redispersed in pure tert-butanol, centrifuged, and vacuum dried until a constant weight was reached (white colour solid, yield $=3.9 \mathrm{~g}$ ).

\subsection{Polymerization of ESO, $\mathrm{PO}$ and $\mathrm{CO}_{2}$}

Terpolymerization was carried out in a $100 \mathrm{~mL}$ stainless steel reactor (Autoclave Engineers, Erie, PA USA) autoclave equipped with a mechanical stirrer and an automatic temperature controller system. The autoclave was first dried at $100{ }^{\circ} \mathrm{C}$ for at least $12 \mathrm{~h}$ then it was cooled down to $25^{\circ} \mathrm{C}$. Subsequently, the reactor was charged with $10 \mathrm{~mL}$ of ESO, $10 \mathrm{~mL}$ of PO and $0.1 \mathrm{~g}$ of dried Co-Zn DMC catalyst. Initially, the reactor was purged twice with $\mathrm{CO}_{2}$ and next slowly pressurized to 4.0 $\mathrm{MPa}$. The reaction temperature was then raised and maintained between 60 and $100{ }^{\circ} \mathrm{C}$ with a stirring speed of $500 \mathrm{rpm}$ to initiate the polymerization reaction. Meanwhile the reaction time was ranging between $6 \mathrm{~h}$ to $72 \mathrm{~h}$. Once the reaction ends, the autoclave was cooled down to room temperature, slowly depressurized and opened. The products obtained were purified by dissolving in dichloromethane, precipitated by excess methanol and then dried at room temperature to a constant weight.

\subsection{Characterizations}

The functionalization of $\mathrm{K}_{3} \mathrm{Co}(\mathrm{CN})_{6}$ and $\mathrm{Co}-\mathrm{Zn}$ DMC catalyst were examined using IR spectroscopy. Absorption spectra were recorded on a Jasco 4100 spectrometer (Jasco International, Tokyo Japan) in attenuated total reflectance (ATR) mode meanwhile spectra of ESO and terpolymerization products were recorded on a

Fig. 1. General structure of polycarbonate.

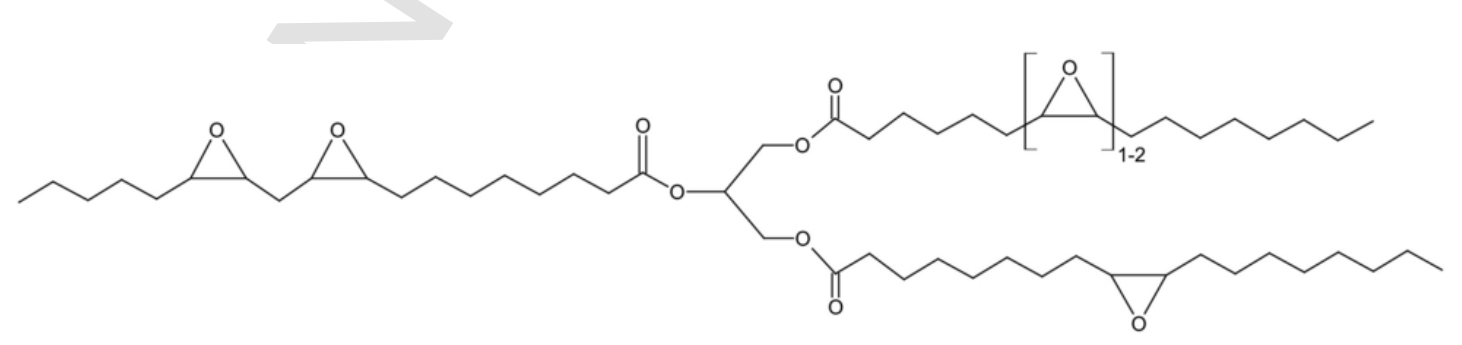

Fig. 2. Structure of ESO. 
Perkin-Elmer 1000 FTIR spectrometer in the wavenumber region of 600 to $4000 \mathrm{~cm}^{-1}$. ${ }^{1} \mathrm{H}$ NMR spectroscopic analysis of ESO and final products was recorded using a Bruker AMX-300 spectrometer at $25^{\circ} \mathrm{C}$. The equipment operated at $300 \mathrm{MHz}$ and all measurements were made by using $\mathrm{CDCl}_{3}$ as solvent. In Gel Permeation Chromatography $(\mathrm{GPC})$ test, the number average molecular weight $\left(M_{n}\right)$ and the polydispersity index (PDI) were determined using a Agilent HPLC equipped with a separation column of PLHFIP gel running at room temperature. Mobile phase is HFIP containing $2.72 \mathrm{~g} \cdot \mathrm{L}^{-1}$ of sodium trifluoroacetate to prevent polyelectrolyte effect. $100 \mu \mathrm{L}$ will be injected and the concentration of each sample will be $0.2 \mathrm{w} / \mathrm{vol} \%$. Calibration was performed with polymethyl methacrylate (PMMA) samples.

\subsection{Solubility test}

A simple test was conducted to check on the solubility of the insoluble polymers. $20 \mathrm{mg}$ of the samples were mixed in $2 \mathrm{~mL}$ of solvent which are chloroform, DMSO, HFIP and toluene at room temperature. The dissolution of the samples in solvent was observed every one hour interval for the first $6 \mathrm{~h}$ and later monitored once a day up to seven days.

\section{Results and discussion}

\subsection{IR of Co-Zn DMC catalyst}

In this study, the DMC catalyst composed of zinc hexacyanometalate was prepared by means of precipitation reaction in a traditional method between $\mathrm{K}_{3} \mathrm{Co}(\mathrm{CN})_{6}$ and metal salt namely $\mathrm{ZnCl}_{2}$ along with tert-butanol as complexing agent. The incorporation of tert-butanol during the preparation of DMC catalyst was claimed could help to heighten the activity of the catalyst (Tharun et al., 2012; Zhang et al., 2011). Shown in Fig. 3 is the IR spectrums of $\mathrm{K}_{3} \mathrm{Co}(\mathrm{CN})_{6}$ and $\mathrm{Zn}-\mathrm{Co}$ DMC catalyst. It was observed that the $v(\mathrm{CN})$ of $\mathrm{K}_{3} \mathrm{Co}(\mathrm{CN})_{6}$ shifted to higher wave number approximately $2193 \mathrm{~cm}^{-1}$ in Co-Zn DMC catalyst. The $v(\mathrm{CN})$ shift to higher frequency is in a good agreement with report by Dharman et al. (2008) which suggest that $\mathrm{CN}^{-}$acts as $\sigma$-donor by donating electrons to the $\mathrm{Co}^{3+}$ and as a $\pi$-electron donor by chelating to $\mathrm{Zn}^{2+}$, which is responsible for raising the $(\mathrm{CN})$ value (Dharman et al., 2008). The presence of complexing agent tert-bu-

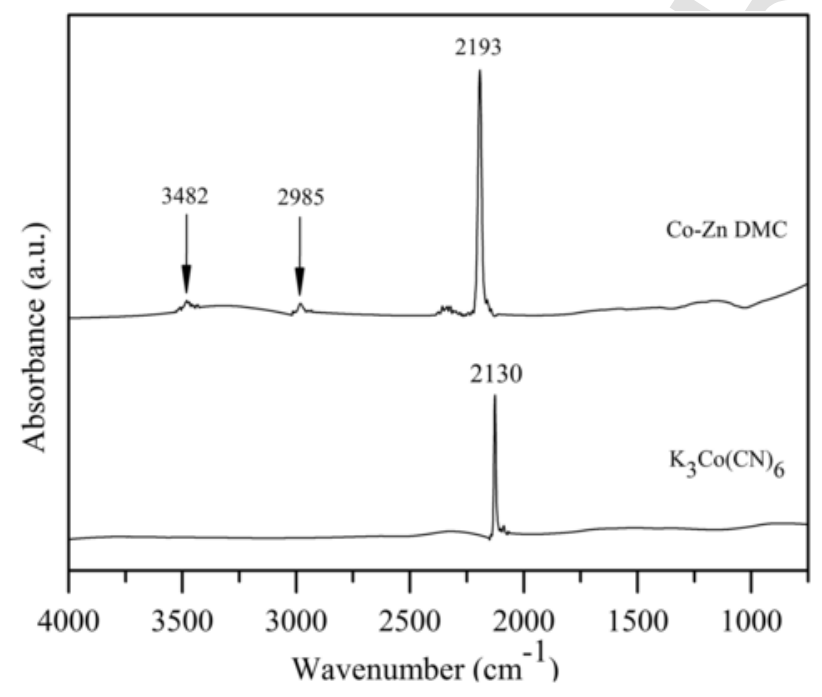

Fig. 3. IR spectra of $\mathrm{K}_{3} \mathrm{Co}(\mathrm{CN})_{6}$ and $\mathrm{Co}-\mathrm{Zn}$ DMC catalyst. tanol, was verified by the $-\mathrm{OH}$ stretching vibration absorption and $\mathrm{C}-\mathrm{H}$ stretching vibration absorption at approximate $3482 \mathrm{~cm}^{-1}$ and $2985 \mathrm{~cm}^{-1}$ respectively (Guo and Lin, 2014).

\subsection{Properties and characterization of terpolymerization products}

The properties of individual products obtained from terpolymerization reaction are tabulated in Table 1. As shown in Table 1, at reaction temperature of $60{ }^{\circ} \mathrm{C}$ and $80{ }^{\circ} \mathrm{C}$ the yield of polymerization products are $62 \%$ and $82 \%$ respectively and reach plateau at $90{ }^{\circ} \mathrm{C}$ with a maximum yield of $86 \%$ meanwhile the productivity was observed to increase from $112 \mathrm{~g}$ product/g catalyst to $154 \mathrm{~g}$ product/g catalyst as the temperature raised from $60{ }^{\circ} \mathrm{C}$ to $90{ }^{\circ} \mathrm{C}$. However, at $100{ }^{\circ} \mathrm{C}$ the productivity decreased slightly to $151 \mathrm{~g}$ product/g catalyst. Meanwhile for the effect of reaction time, in general the longer the reaction time, the higher the yield and productivity. When the reaction time varied from $6 \mathrm{~h}$ to $72 \mathrm{~h}$, the yield recorded ranging between 72 and $90 \%$ whereas productivity was in-between 129 and $161 \mathrm{~g}$ product/g catalyst.

Analysis of the products by GPC revealed the $M_{n}$ for all samples prepared ranges between $1983 \mathrm{~g} / \mathrm{mol}$ to $6498 \mathrm{~g} / \mathrm{mol}$. These values are comparable with the $M_{n}$ reported elsewhere (Dai et al., 2016; Guo and Lin, 2014; Wei et al., 2013). Considering the starting material used for this reaction comprises of a mixture of natural ESO and commercial $\mathrm{PO}$, thus this has shown a good indication of the viability of natural ESO as a precursor for the synthesis of vegetable oil based polymer. However, two samples prepared at 90 and $100{ }^{\circ} \mathrm{C}$ were unable to be characterized by GPC perhaps due to the formation of a cross-linked material.

To further validate the possibility of the formation of a cross-linked material, a simple solubility test was conducted. From the observation, the two samples prepared at higher temperature were insoluble in all solvent (chloroform, DMSO, HFIP and toluene). These results confirm that the probability of the two samples obtained at higher temperature is both cross-linked materials.

\subsection{Analysis of products}

Polycarbonates and cyclic carbonates are the two types of products generally produced from the reaction of $\mathrm{CO}_{2}$ with epoxide (Scheme 1). In an ideal copolymerization reaction, an alternating insertion of $\mathrm{CO}_{2}$ and epoxide will take place in the growing polymer chain. However, the consecutive insertion of two epoxides may also happen and leads to the formation of ether bonds in the copolymer which typically is undesired. The consecutive insertion of two $\mathrm{CO}_{2}$ molecules has never been observed as this is strongly disfavored from a thermodynamic perspective (Coates and Moore, 2004).

Table 1

Data on the terpolymerization of ESO, $\mathrm{PO}$ and $\mathrm{CO}_{2}$ under $\mathrm{Co}-\mathrm{Zn} \mathrm{DMC}$ catalyst.

\begin{tabular}{|c|c|c|c|c|c|}
\hline Entry & $\begin{array}{l}\text { Reaction } \\
\text { temp. }\left({ }^{\circ} \mathrm{C}\right)\end{array}$ & $\begin{array}{l}\text { Time } \\
\text { (h) }\end{array}$ & $\begin{array}{l}\text { Yield } \\
(\%)\end{array}$ & $\begin{array}{l}\text { Productivity g } \\
\text { product/g catalyst }\end{array}$ & $M_{n} / M_{w} / \mathrm{PDI}$ \\
\hline 1 & 60 & 24 & 62 & 112 & $2323 / 4251 / 1.8$ \\
\hline 2 & 80 & 24 & 82 & 142 & $3834 / 4962 / 1.3$ \\
\hline 3 & 90 & 24 & 86 & 154 & $\begin{array}{c}\text { Crosslinked } \\
\text { material }\end{array}$ \\
\hline 4 & 100 & 24 & 86 & 151 & $\begin{array}{c}\text { Crosslinked } \\
\text { material }\end{array}$ \\
\hline 5 & 80 & 6 & 72 & 130 & $6498 / 8462 / 1.3$ \\
\hline 6 & 80 & 48 & 90 & 161 & $1983 / 5696 / 2.9$ \\
\hline 7 & 80 & 72 & 75 & 129 & $3541 / 4246 / 1.2$ \\
\hline
\end{tabular}

Reaction conditions: volume of $\mathrm{ESO}=10 \mathrm{~mL}$, volume of $\mathrm{PO}=10 \mathrm{~mL}, \mathrm{Co}-\mathrm{Zn} \mathrm{DMC}$ amount $=0.1 \mathrm{~g}$, pressure of $\mathrm{CO}_{2}=4.0 \mathrm{MPa}$. 


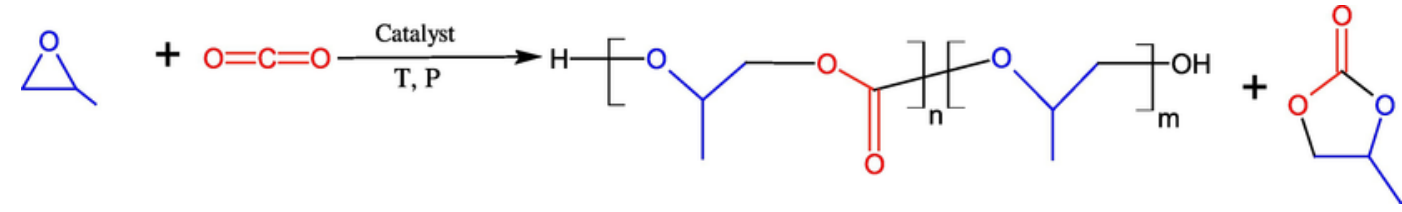

Scheme 1. Copolymerization of $\mathrm{CO}_{2}$ and epoxide.

In this work, the vegetable oil based polymer synthesized from the terpolymerization reaction of $\mathrm{ESO}, \mathrm{PO}$ and $\mathrm{CO}_{2}$ with the presence of $\mathrm{Co}-\mathrm{Zn} \mathrm{DMC}$ catalyst is a polycarbonate, specifically a poly(propylene carbonate). At the same time, cyclic carbonate and polyether linkages were also detected. The extent of carbonate and ether backbone could be easily traced by IR and ${ }^{1} \mathrm{H}$ NMR spectroscopies of the resultant polymers. Fig. 4 shows the FTIR spectra of terpolymerization product prepared at reaction temperature and reaction time of $80^{\circ} \mathrm{C}$ and $6 \mathrm{~h}$ respectively. It was pronounced from the spectra the intense $\mathrm{C}=\mathrm{O}$ asymmetric vibration absorption peak at approximately $1745 \mathrm{~cm}^{-1}$. Together with this, the presence of absorption peak around $1256 \mathrm{~cm}^{-1}$, which correspond to $\mathrm{C}-\mathrm{O}$ stretching vibration absorption, provides confirmation for the presence of both carbonate and ether backbone in the resultant terpolymer. Besides, the characteristic absorption peak of the $\mathrm{C}=\mathrm{O}$ stretching vibrations of cyclic carbonate was detected at $1810 \mathrm{~cm}^{-1}$. The FTIR spectrums of the remaining samples prepared illustrate the same characteristic peaks and given in Supplementary A1 and A2.

All polymers were subjected to ${ }^{1} \mathrm{H} \mathrm{NMR}$ analysis in $\mathrm{CDCl}_{3}$, and a representative spectrum of the polymer produced by Co-Zn DMC catalyst at $80^{\circ} \mathrm{C}$ and $6 \mathrm{~h}$ is shown in Fig. 5, together with that of ESO monomer for the comparison. In general, based on the ${ }^{1} \mathrm{H}$ NMR analysis it was confirmed that the resultant products from the terpolymerization of $\mathrm{ESO}, \mathrm{PO}$ and $\mathrm{CO}_{2}$ consist of chain of poly(propylene carbonate) bonded to the triglyceride. At the same time the presence of polyether linkages and cyclic carbonate are also detected in the products. As mentioned by Zhang et al. (2014), the formation of the ether units is usually thermodynamically favorable during $\mathrm{Co}-\mathrm{Zn}(\mathrm{III})$ DMCC catalysis (Zhang et al., 2014). The peaks at $\delta 2.8-3.2$ ppm region related to epoxy proton are apparent in both spectra of ESO and the polymer product. The signal of epoxy proton in the resultant polymer signify that a fraction of epoxide was unreacted during the poly-

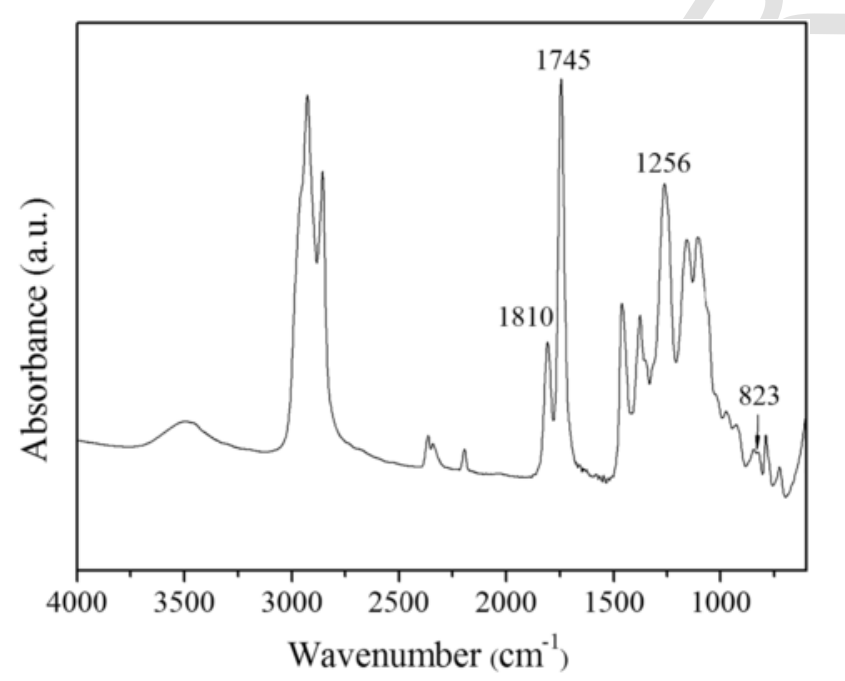

Fig. 4. FTIR spectra for purified sample prepared at $T=80^{\circ} \mathrm{C}$ and $t=6 \mathrm{~h}$ (entry no. 5 in Table 1).

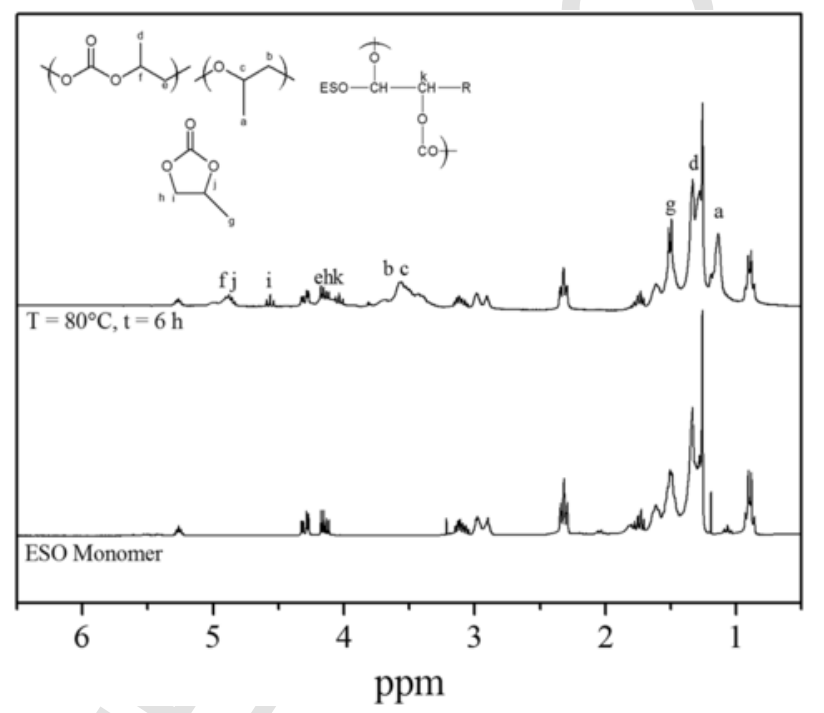

Fig. 5. ${ }^{1} \mathrm{H}$ NMR spectra for purified sample prepared at $T=80^{\circ} \mathrm{C}$ and $t=6 \mathrm{~h}$ (entry no. 5 in Table 1).

merization reaction probably due to the steric hindrance owing to the long chain structure of triglyceride. Also notable are the methine proton $-\mathrm{CH}_{2}-\mathrm{CH}-\mathrm{CH}_{2}-$ of the glycerol backbone at $\delta 5.1-5.3 \mathrm{ppm}$ and methylene protons $-\mathrm{CH}_{2}-\mathrm{CH}-\mathrm{CH}_{2}-$ of the glycerol backbone at $\delta$ 4.1-4.3 ppm which revealed triglyceride structure of ESO is not disturbed (Liu et al., 2013).

The percentage incorporation of ESO in the polymer was calculated from the integrated peak areas taking the terminal methyl signals as an internal reference standard. Eq. (1) was used in the calculation as per following:

$$
\begin{aligned}
F_{\text {ESO }}= & \frac{A_{\text {reacted epoxy }}}{A_{\text {reacted epoxy }}+A_{\text {polycarbonate }}+A_{\text {ether unit }}} \\
& \times 100
\end{aligned}
$$

where, $A_{\text {reacted epoxy }}$ is the integrated area of the methine epoxy proton at $\delta 4.07-4.16 \mathrm{ppm}$ (Salih et al., 2015) meanwhile the $A_{\text {polycarbonate }}$ and $A_{\text {ether unit }}$ are the integrated peak area of the methine proton of polycarbonate unit $(\delta 5.10 \mathrm{ppm})$ and ether unit $(\delta 3.5 \mathrm{ppm})$ respectively. Note that the peak of reacted epoxy overlapped with the peaks of cyclic carbonate and methylene protons of the glycerol backbone, thus these peaks areas were subtracted in the calculation. The percentage incorporation of ESO in the polymer is only $7.8 \%$ at the shortest reaction time and in general the amount is found to be decreasing with the elevation of reaction temperature and prolonged reaction time (Table 2). The amount of ESO incorporated in the polymer obtained is quite low as ESO is less reactive than PO. Even so, considering that this is the first attempt utilizing ESO as one of the starting material in the polymerization reaction with $\mathrm{CO}_{2}$, thus the re- 
Table 2

Percentage incorporation of ESO and amount of cyclic carbonate in the terpolymerization products.

\begin{tabular}{lllll}
\hline Entry & Reaction temp. $\left({ }^{\circ} \mathrm{C}\right)$ & Time $(\mathrm{h})$ & $F_{\text {ESO }}{ }^{\mathrm{a}}(\%)$ & $W_{\mathrm{CC}}{ }^{\mathrm{b}}(\mathrm{wt} \%)$ \\
\hline 1 & 60 & 24 & 6.7 & 20.6 \\
2 & 80 & 24 & 6.0 & 18.8 \\
3 & 90 & 24 & 0.8 & 10.4 \\
4 & 100 & 24 & 0.0 & 9.5 \\
5 & 80 & 6 & 7.8 & 14.1 \\
6 & 80 & 48 & 3.2 & 9.1 \\
7 & 80 & 72 & 6.2 & 12.6 \\
\hline
\end{tabular}

Reaction conditions: volume of ESO $=10 \mathrm{~mL}$, volume of $\mathrm{PO}=10 \mathrm{~mL}, \mathrm{Co}-\mathrm{Zn} \mathrm{DMC}$ amount $=0.1 \mathrm{~g}$, pressure of $\mathrm{CO}_{2}=4.0 \mathrm{MPa}$.

${ }^{\text {a }} F_{\text {ESO }}(\%)$ indicates the molar fraction of ESO incorporated in the polymer product.

b $W_{\mathrm{CC}}(\mathrm{wt} \%)$ indicates the weight percentage of cyclic carbonate in the total product.

sults gave a good sign of utilizing renewable bio-resources for this particular reaction in the future.

The weight percentage of cyclic carbonate, $\left(W_{\mathrm{CC}}\right)$ can be determined using the formula as below:

$$
\begin{aligned}
& W_{\mathrm{CC}} \\
& =\frac{\text { Mass }_{\text {cyclic carbonate }} \times A_{\text {cycl }}}{\text { Mass }_{\text {ether unit }} \times A_{\text {ether unit }}+\text { Mass }_{\text {cyclic carbonate }} \times\left(A_{\text {cyclic Cark }}\right.} \\
& \quad \times 100
\end{aligned}
$$

where, $A_{\text {cyclic carbonate }}, A_{\text {ether unit }}$ and $A_{\text {polycarbonate }}$ are the integrated areas of $-\mathrm{CH}_{3}$ protons of cyclic carbonate $(\delta 1.50 \mathrm{ppm})$, polyether $(\delta$ $1.14 \mathrm{ppm})$ and polycarbonate $(\delta 1.33 \mathrm{ppm})$ accordingly meanwhile $A_{\mathrm{ESO}}$ represents by the area of terminal methyl protons of ESO $(\delta$ $0.89 \mathrm{ppm})$. The calculated results are tabulated in Table 2. Surprisingly in this study, the weight percentage of the cyclic carbonate in the product was found to decrease with increasing reaction temperature. This is in contrast with the report mentioned elsewhere where stated that the formation of thermodynamically stable cyclic carbonate is highly favored at higher reaction temperature (Li and Niu, 2011). Another important finding was that the signal of ether unit becomes more significance at higher reaction temperature (Supplementary A3). A possible explanation for this might be that the homopolymerization of epoxides are more dominant during the terpolymerization reaction considering that the concentration of $\mathrm{CO}_{2}$ supplied was fewer as the temperature raised from $60{ }^{\circ} \mathrm{C}$ to $100{ }^{\circ} \mathrm{C}$ (Henry's law) whilst the amount of both epoxides were kept constant (Tang et al., 2013).

\section{Conclusions and outlook}

The results of this study demonstrated that under the reaction conditions studied, the resultant terpolymerization products comprise of a mixture of poly(propylene carbonate), cyclic carbonate and polyether unit. The constituent of the resultant products have been verified by the FTIR and ${ }^{1} \mathrm{H}$ NMR analysis. Polymeric product with yield of $72 \%$ and $M_{n}$ of $6498 \mathrm{~g} / \mathrm{mol}$ was recorded at reaction temperature of $80^{\circ} \mathrm{C}$ and reaction time of $6 \mathrm{~h}$. The resultant polymer obtained through this research work has proven the viability of utilizing natural epoxide, namely ESO for the production of bio-based polymer.

In order to incorporate the green material in the formulation, initially the use of natural epoxide was presented as partial replacement of petroleum based epoxide. However, with persistent and extensive research effort, natural epoxide may compete well with their petro- leum based counterparts in terms of properties, performance and applications. The prospect of using ESO as a substitute to the petroleum based epoxide may as well provide solutions to increasing environmental and energy concern. Nevertheless, countless challenges must be overcome to develop better vegetable oil-based polymers.

\section{Acknowledgments}

The authors would like to thank Spanish Ministry of Economy and Competitiveness (Program RETOS, Grant No. MAT2016-80045-R) for the financial support of this work. Majlis Amanah Rakyat and Universiti Kuala Lumpur, Malaysia are both acknowledged for funding a fellowship to make this study possible.

\section{Appendix A. Supplementary data}

Supplementary data to this article can be found online at http://dx. doi.org/10.1016/j.scitotenv.2017.04.184.

\section{References}

Ang, R.-R., Tin Sin, L., Bee, S.-T., Tee, T.-T., Kadhum, A.A.H., Rahmat, A.R., et al., 2015. A review of copolymerization of green house gas carbon dioxide and oxiranes to produce polycarbonate. J. Clean. Prod. 102, 1-17.

Coates, G.W., Moore, D.R., 2004. Discrete metal-based catalysts for the copolymerization of $\mathrm{CO}_{2}$ and epoxides: discovery, reactivity, optimization, and mechanism. Angew. Chem. Int. Ed. 43, 6618-6639.

Costa, C.S.M.F., Fonseca, A.C., Moniz, J., Godinho, M., Serra, A.C., Coelho, J.F.J., 2016. Soybean and coconut oil based unsaturated polyester resins: thermomechanical characterization. Ind. Crop. Prod. 85, 403-411.

Coutris, C., Macken, A.L., Collins, A.R., El Yamani, N., Brooks, S.J., 2015. Marine ecotoxicity of nitramines, transformation products of amine-based carbon capture technology. Sci. Total Environ. 527-528, 211-219.

Dai, C., Zhu, Q., Pang, H., Zhu, L., Lin, Q., 2016. Rapid copolymerization of carbon dioxide and propylene oxide catalyzed by double metal cyanide complexes in an ultrasonic field. Mater. Lett. 180, 89-92.

Darensbourg, D.J., Chung, W.-C., 2014. Availability of other aliphatic polycarbonates derived from geometric isomers of butene oxide and carbon dioxide coupling reactions. Macromolecules 47, 4943-4948.

Dharman, M.M., Ahn, J.-Y., Lee, M.-K., Shim, H.-L., Kim, K.-H., Kim, I., et al., 2008 Moderate route for the utilization of $\mathrm{CO}_{2}$-microwave induced copolymerization with cyclohexene oxide using highly efficient double metal cyanide complex catalysts based on $\mathrm{Zn}_{3}\left[\mathrm{Co}(\mathrm{CN})_{6}\right]$. Green Chem. 10, 678-684.

Guo, Z., Lin, Q., 2014. Coupling reaction of $\mathrm{CO}_{2}$ and propylene oxide catalyzed by DMC with co-complexing agents incorporated via ball milling. J. Mol. Catal. A Chem. 390, 63-68.

Ingrao, C., Tricase, C., Cholewa-Wójcik, A., Kawecka, A., Rana, R., Siracusa, V., 2015. Polylactic acid trays for fresh-food packaging: a carbon footprint assessment. Sci. Total Environ. 537, 385-398.

Inoue, S., Koinuma, H., Tsuruta, T., 1969. Copolymerization of carbon dioxide and epoxide. Journal of Polymer Science Part B: Polymer Letters 7, 287-292.

Li, H., Niu, Y., 2011. Alternating copolymerization of $\mathrm{CO}_{2}$ with propylene oxide and terpolymerization with aliphatic epoxides by bifunctional cobalt Salen complex. Polym. J. 43, 121-125.

Li, Z., Qin, Y., Zhao, X., Wang, F., Zhang, S., Wang, X., 2011. Synthesis and stabilization of high-molecular-weight poly(propylene carbonate) from $\mathrm{ZnCo-based}$ double metal cyanide catalyst. Eur. Polym. J. 47, 2152-2157.

Liu, Z., Shah, S.N., Evangelista, R.L., Isbell, T.A., 2013. Polymerization of euphorbia oil with Lewis acid in carbon dioxide media. Ind. Crop. Prod. 41, 10-16.

Meng, Q., Cheng, R., Li, J., Wang, T., Liu, B., 2016. Copolymerization of $\mathrm{CO}_{2}$ and propylene oxide using $\mathrm{ZnGA} / \mathrm{DMC}$ composite catalyst for high molecular weight poly(propylene carbonate). Journal of $\mathrm{CO}_{2}$ Utilization 16, 86-96.

Miao, S., Wang, P., Su, Z., Zhang, S., 2014. Vegetable-oil-based polymers as future polymeric biomaterials. Acta Biomater. 10, 1692-1704.

Oh, H.J., Ko, Y.S., 2013. Effect of polymerization conditions on the polymer properties of $\mathrm{CO}_{2}$-cyclohexene oxide copolymer prepared by double metal cyanide catalyst. J. Ind. Eng. Chem. 19, 1939-1943.

Sakakura, T., Choi, J.-C., Yasuda, H., 2007. Transformation of carbon dioxide. Chem. Rev. 107, 2365-2387.

Salih, A., Ahmad, M., Ibrahim, N., Dahlan, K., Tajau, R., Mahmood, M., et al., 2015. Synthesis of radiation curable palm oil-based epoxy acrylate: NMR and FTIR spectroscopic investigations. Molecules 20, 14191. 
Sebastian, J., Srinivas, D., 2014. Effects of method of preparation on catalytic activity of $\mathrm{Co}-\mathrm{Zn}$ double-metal cyanide catalysts for copolymerization of $\mathrm{CO}_{2}$ and epoxide. Appl. Catal. A Gen. 482, 300-308.

Tang, L., Xiao, M., Xu, Y., Wang, S., Meng, Y., 2013. Zinc adipate/tertiary amine catalytic system: efficient synthesis of high molecular weight poly(propylene carbonate). J. Polym. Res. 20, 1-9.

Taşcı, Z., Ulusoy, M., 2012. Efficient pathway for $\mathrm{CO}_{2}$ transformation to cyclic carbonates by heterogeneous $\mathrm{Cu}$ and $\mathrm{Zn}$ salen complexes. J. Organomet. Chem. 713, 104-111.

Tharun, J., Dharman, M.M., Hwang, Y., Roshan, R., Park, M.S., Park, D.-W., 2012. Tuning double metal cyanide catalysts with complexing agents for the selective production of cyclic carbonates over polycarbonates. Appl. Catal. A Gen. 419-420, 178-184.

Trott, G., Saini, P.K., Williams, C.K., 2016. Catalysts for $\mathrm{CO}_{2}$ /epoxide ring-opening copolymerization. Philos. Trans. R. Soc. A Math. Phys. Eng. Sci. 374

US Food and Drug Administration, 2014. Bisphenol A (BPA): Use in Food Contact Application. US Food and Drug Administration.
Wang, Z., Bu, Z., Cao, T., Ren, T., Yang, L., Li, W., 2012. A novel and recyclable catalytic system for propylene carbonate synthesis from propylene oxide and $\mathrm{CO}_{2}$. Polyhedron 32, 86-89.

Wei, R.-J., Zhang, X.-H., Du, B.-Y., Fan, Z.-Q., Qi, G.-R., 2013. Selective production of poly(carbonate-co-ether) over cyclic carbonate for epichlorohydrin and $\mathrm{CO}_{2}$ copolymerization via heterogeneous catalysis of $\mathrm{Zn}-\mathrm{Co}$ (III) double metal cyanide complex. Polymer 54, 6357-6362.

Xia, Y., Larock, R.C., 2010. Vegetable oil-based polymeric materials: synthesis, properties, and applications. Green Chem. 12, 1893-1909.

Zhang, X.-H., Wei, R.-J., Sun, X.-K., Zhang, J.-F., Du, B.-Y., Fan, Z.-Q., et al., 2011 Selective copolymerization of carbon dioxide with propylene oxide catalyzed by a nanolamellar double metal cyanide complex catalyst at low polymerization temperatures. Polymer

Zhang, Y.-Y., Zhang, X.-H., Wei, R.-J., Du, B.-Y., Fan, Z.-Q., Qi, G.-R., 2014. Synthesis of fully alternating polycarbonate with low $\mathrm{Tg}$ from carbon dioxide and bio-based fatty acid. RSC Adv. 4, 36183-36188. 